Original Article

\title{
EFFECTS OF LACTOBACILLUS JOHNSONII AJ5 METABOLITES ON NUTRITION, NOSEMA CERANAE DEVELOPMENT AND PERFORMANCE OF APIS MELLIFERA L.
}

\author{
Fiorella G. De Piano*1,2,3 \\ Matias Maggi2,5 \\ María C. Pellegrini2,3 \\ Noelia M. Cugnata 2,5 \\ Nicolas Szawarski ${ }^{2,5}$ \\ Franco Buffa ${ }^{6}$ \\ Pedro Negri 2,5 \\ Sandra R. Fuselli2,3 \\ Carina M. Audisio ${ }^{4,5}$ \\ Sergio R. Ruffinengo ${ }^{1,2}$ \\ ${ }^{1}$ Unidad Integrada Balcarce (FCA-UNMdP/EEA-INTA), Ruta 226, km 73,5 ( ${ }^{*} \mathrm{CC}$ \\ 276-B7620ZAA) Balcarce 7620, Argentina \\ ${ }^{2}$ Centro de Investigaciones en Abejas Sociales (CIAS), Facultad de Ciencias Exactas \\ y Naturales, Universidad Necional de Mar del Planta, Funes 3350 (B7602AYL), Mar \\ del Plata 7600, Argentina. \\ ${ }^{3}$ Comision de Investigaciones Cienificas (CIC). Calle 526 e/10 y 11, La Plata 1900, \\ Argentina \\ ${ }^{4}$ Instituto de Investigaciones para la Industria Química (INIQUI)/Facultad \\ de Ingeniería, Universidad Nacional de Salta. Av. Bolivia 5150, Salta 4400, \\ Argentina \\ ${ }^{5}$ Consejo Nacional de Investigaciones Cienificas y Técnicas (CONICET). Av. Rivadavia \\ 1917 (C1033AAJ) Ciudad Autónoma de Buenos Aires, Argentina \\ ${ }^{6}$ sez. Patologia vegetale ed Entomologia, Dipartimento di Agraria, Universita di \\ Sassari, Italia \\ *corresponding author: fiorelladepiano@gmail.com \\ Received: 10 May 2016; accepted: 13 February 2017
}

Abstract

The European honey bee (Apis mellifera $\mathrm{L}$.) is known to be affected by such stress factors as pathogen load, poor nutrition and depressed immunity. Nosema ceranae is one of the main parasites that affect colony populations. The relationship between the stress factors and honey bee-bacteria symbiosis appears as an alternative to enhance bee health. The aim of this study was to evaluate the effect of the oral administration of bacterial metabolites produced by Lactobacillus johnsonii AJ5 on nutritional parameters, the $\boldsymbol{N}$. ceranae development and the performance of $A$. mellifera colonies. Laboratory assays were performed and demonstrated that the bacterial metabolites did not have a toxic effect on bees. Field trial showed an increase of colonies population over time. Also, a decreasing trend of fat bodies per bee was detected in all colonies but there were no evident changes on abdomen protein content at the end of the assay. Lastly, $N$. ceranae prevalence showed a tendency to reduce with the organic acids. Future studies should be performed to increase our knowledge of the physiological effects of bacterial metabolites on the health of bee colonies.

Keywords: Apis mellifera, bacterial metabolites, Lactobacillus johnsonii AJ5, Nosema ceranae, nutrition 


\section{INTRODUCTION}

The beekeeping world is facing a complex scenario. A variety of health and nutritional aspects has generated adverse conditions that negatively affect the evolution and normal development of bee colonies. A recent trouble associated with this situation is colony loss which is closely related to chronic stressors, including poor nutrition, increased pathogen loads and genetic diversity (Naug, 2009; vanEngelsdorp et al., 2009; Neumann \& Carreck, 2010). The composition and function of honey bee microbiota is a critical factor to reduce nutritional stress and both affect the host's immune system even though have not yet been fully characterized (Dillon \& Dillon, 2004; Mattila et al., 2012; Vásquez et al., 2012).

The European honey bee is affected by several pathologies. One of them is Nosemosis which has a great impact on the development of not only the insect (Fries, 1988; Higes et al., 2007) but also the colony (Higes et al., 2008; Paxton, 2010). This disease is caused by two microsporidia species, Nosema apis and Nosema ceranae (Fries et al., 1996; Higes, Martín, \& Meana, 2006; Forsgren \& Fries, 2010), which are both obligate intracellular parasites of the ventricular epithelial cells of adult bees (Fries, 1988; Higes et al., 2007). $N$. ceranae is a microsporidia more virulent than $N$. apis (Forsgren \& Fries, 2010). Apart from causing ventricular epithelium lesions, it suppresses humoral and cellular defenses (Alaux et al., 2010a) and produces a decrease in vitellogenin expression (Antúnez et al., 2009). These nutritional and immunological depressions result in decreased worker longevity, a precocious onset of foraging and a loss of foragers in the field. Thus, N. ceranae is considered one of the factors that contribute to colony depopulation also associated with the recent colony collapse disorder (CCD) (Oldroyd, 2007; Higes et al., 2008; Paxton, 2010).

In order to overcome the pathologies, continuous chemical applications have been employed incorrectly producing undesirable results such as resistant strains (Maggi et al., 2009, 2010, 2011) and residues on beehive products (Bogdanov,
2006; Medici, 2010; Simion et al., 2011). Consequently, antibiotics have been banned in most EU member states. In this context, natural and non-contaminant alternatives have been incorporated to strengthen nutrition and immune response in colonies and indirectly parasite tolerance. Adequate nutrition of $A$. mellifera is known to contribute to colony development (Brodschneider \& Crailsheim, 2010) and enhance their individual and social immunocompetence (Alaux et al., 2010b). There has been a special emphasis on the study of mutualistic relationships between bees and their coexisting microorganisms (Mattila et al., 2012; Vásquez et al., 2012). These are involved in many aspects of host life, physiology and evolution, including nutrition, reproduction, immune homeostasis, defence and speciation (Crotti et al., 2012).

Eight bacterial species clusters dominate A. mellifera workers' gut, comprising over 95\% of the whole community (Moran, 2015). Even if the species-level diversity is low, the strain diversity depicts more metabolic functions that benefit hosts (Alberoni et al., 2016). Microbial gut symbionts of social insects have the enzymatic capability (i.e., cellulases, hemicellulases and lignase) to uptake the energy from a plant-based diet (Engel et al., 2012; Newton et al., 2013). Besides, these microorganisms produce fatty acids, amino acids, metabolites (Gündüz \& Douglas, 2009) and vitamins required for honey bees (Brodschneider \& Crailsheim, 2010). Whereas the functions above are related to nutrition, comparative analysis of gene contents suggests that microbiota contributes to host interaction, biofilm formation (Engel et al., 2012; Vásquez et al., 2012) and antimicrobial action (Alberoni et al., 2016). There is strong evidence of an increase of antimicrobial peptide (AMPs) production induced by honey bee gut bacteria (Evans \& Lopez, 2004; Jefferson et al., 2013; Yoshiyama et al. 2013; Janashia \& Alaux, 2016). Several in vitro trials confirmed the hability of lactobacilli and bifidobacteria to inhibit honey bee pathogens, in particular Paenibacillus larvae, Melissococcus plutonius and Ascosphaera apis (Forsgren et al., 2009; Sabaté et al., 2009; Yoshiyama \& Kimura, 2009; Audisio 
et al., 2011; Vásquez et al., 2012). Similarly, a reduction in $N$. ceranae intensity was reported when a Bacillus spp. strain culture (Sabaté et al., 2012) or metabolic products of specific Bacillus spp. (Porrini et al., 2010) and Lactobacillus spp. (Maggi et al., 2013) were administered to bees. Over the last years, honey bee researchers have been working hard to analyze the composition and function of honey bee microbiota (Engel et al., 2012; Mattila et al., 2012; Vásquez et al., 2012; Alberoni et al., 2016) to use it as an alternative to deal with nutritional and immunological problems (Crotti et al., 2012; Moran, 2015). Furthermore, much effort has been focused on developing natural formulations to improve colony performance and consequently mitigate the negative effects of major diseases. In this sense a specific lactic acid bacteria (LAB) isolated from bee gut was selected on the base of the potential probiotic properties on animals of this bacterial group (Audisio, 2016). The aim of this study was to determine the effect of the oral administration of bacterial metabolites produced by Lactobacillus johnsonii AJ5 on the performance of $A$. mellifera colonies, the $N$. ceranae development and nutritional parameters.

\section{MATERIAL AND METHODS}

\section{Biological material: bees, hive location and experimental conditions}

The field trial was carried out in an experimental apiary located $10 \mathrm{~km}$ away south of Mar del Plata, Argentina (3755'48"S 57\%40'59"0). Experiments were conducted in spring, between October and December 2012. The experiments were carried out on colonies of $A$. mellifera $L$. kept in standard Langstroth hives. A total of ten hives, previously standardized, was used for the assays. Each one consisted of five combs covered with adult bees, one open brood comb, two sealed brood combs and one open frame full of honey and pollen. The queen was one-year old. Colonies inspections were inspected at midday.

\section{Bacterial metabolites synthesis}

The metabolites synthesized by Lactobacillus johnsonii AJ5 (Genbank access code EU428008) were recovered in the cell-free supernatant (CFS) according to Audisio et al. (2011). This lactic acid bacterium was grown in MRS broth (MRS, Britania, Argentina) for $24 \mathrm{~h}$ at $37^{\circ} \mathrm{C}$ under microaerophilic conditions (7\% v/v $\mathrm{O}_{2}$ and $14 \%$ $\mathrm{v} / \mathrm{v} \mathrm{CO}_{2}$ ). After that, the CFS was retrieved by centrifuging $\left(10,000 \mathrm{~g}, 10^{\circ} \mathrm{C}, 15 \mathrm{~min}\right)$, filter-sterilized $(0.22 \mu \mathrm{m})$ and kept at $4^{\circ} \mathrm{C}$ until its use.

\section{Organic acids characterization and quanti- fication}

The characterization and the concentration of the organic acids produced by L. johnsonii AJ5 was performed by HPLC (Audisio et al., 2011). The CFS from an MRS culture was deproteinized and filter-sterilized $(0.45 \mu \mathrm{m})$ before the HPLC analyses. The sample amount injected was 20 $\mu \mathrm{L}$. The column temperature was $55^{\circ} \mathrm{C}$ and the flow rate of the $\mathrm{H}_{2} \mathrm{SO}_{4} 10 \mathrm{mM}$ mobile phase was $0.6 \mathrm{~mL} / \mathrm{min}$. Detection was carried out by determining the refraction index using a 2142LKB Differential Refractometer. The chromatography column (Rezec Organic Acid, Phenomenex) had a diameter of $7.8 \mathrm{~mm}$ and a length of 300 $\mathrm{mm}$. Peak profiles, integration, and quantification were obtained with a CR601 Shimadzu chromatopac integrator (Shimadzu Corporation, Analytical Instrument Division, Kyoto, Japan). Samples were duplicated.

\section{Toxicity of bacterial metabolite on honey bees}

Honey bees were confined individually inside plastic containers (length: $3 \mathrm{~cm}$; diameter: 3 $\mathrm{cm})$ with an internal feeder, a sponge soaked in water ( $65 \mu /$ day) and adequate ventilation. They were daily supplied with $80 \mu$ of each following dose of CFS on syrup 2:1 (water:sugar): 1, 6, 20 and $40 \%$ v/v. Two controls were performed: i) sugar syrup 2:1 and ii) a solution of MRS broth and syrup $(6.25 \% \mathrm{v} / \mathrm{v})$. Each treatment was replicated 30 times. Individual bee mortality per treatment was recorded at 24, 48 and 72 h. Incubation conditions were $33^{\circ} \mathrm{C} \pm 1.5$ and $70 \% \pm 3$ relative humidity $(\mathrm{RH})$. All tests were conducted with nurse bees between 24 and 48 $\mathrm{h}$ which were obtained from sealed brood combs 
Table 1

Summary of the cell-free supernatant (CFS) and MRS broth application (1, 2, 3 and 4) and time of sampling for the variables analyzed $(X)$. $T_{0}$ : initial time, $T_{1}$ : one week after the start of trial, $\mathrm{T}_{2}$ : two weeks after the start of trial, $\mathrm{T}_{3}$ : three weeks after the start of trial, $\mathrm{T}_{4}$ : five weeks after the start of trial

\begin{tabular}{lccccc}
\hline & $\mathrm{T}_{0}$ & $\mathrm{~T}_{1}$ & $\mathrm{~T}_{2}$ & $\mathrm{~T}_{3}$ & $\mathrm{~T}_{4}$ \\
\hline CFS and MRS application & 1 & 2 & 3 & 4 & \\
Sampling of colony development & $\mathrm{X}$ & & $\mathrm{X}$ & & $\mathrm{X}$ \\
Sampling for fat bodies & $\mathrm{X}$ & & $\mathrm{X}$ & & $\mathrm{X}$ \\
Sampling for soluble protein & $\mathrm{X}$ & & $\mathrm{X}$ & & $\mathrm{X}$ \\
N. ceranae sampling & $\mathrm{X}$ & & $\mathrm{X}$ & & $\mathrm{X}$ \\
\hline
\end{tabular}

in the incubator. The emerged bees endured 3-4 h of starvation.

\section{CFS administration and time of sampling} on bee colonies

Treatments were administrated in syrup 2:1 by a Doolittle feeder. Five colonies (treated group) received the CFS and another five colonies (control group) sterile MRS broth. Colonies received a first dose (attack dose, TO: initial time) of $50 \mathrm{ml}$ followed by three weekly applications of $10 \mathrm{ml}$ (T1: second application, T2: third application, T3: fourth application), all of them in 500 $\mathrm{ml}$ of syrup 2:1 (Tab. 1). To evaluate the effects of CFS administration on colony, bee-colony parameters, fat bodies, soluble protein and $N$. ceranae load, samples were taken before each treatment application $\left(T_{0}\right.$ and $\left.T_{2}\right)$ and one week after the last application ( $T_{4}$, Tab. 1).

\section{Colony bee: parameters tested}

The parameters considered to qualify the general state of the colonies during the CFS in field application (Tab.1) were: i) number of combs fully covered with bees (estimated as number of combs covered with adult bees), ii) open and sealed brood areas (according to Branco, Kid \& Pickard, 1999) and iii) quantity of honey and pollen (estimated as number of combs covered with honey or pollen, respectively).

\section{Determination of fat bodies and soluble protein}

Samples of 25 nurse bees per colony, under each treatment and at each sample time $(n=25)$, were collected from the brood nest and frozen until fat bodies and soluble protein were determined
(Tab. 1). Fat bodies were measured according to Wilson-Rich et al. (2008). Abdomens were severed from thoraces and dried for three days at room temperature and then were weighed and washed in ethyl ether for $24 \mathrm{~h}$ until the fat as dissolved. The abdomens were dried for three days and weighed again. The fat body was calculated as the percentage change in abdominal weight after the ethyl ether wash (Ellers, 1996).

Soluble protein content was measured according to protocol by Bowen-Walker \& Gunn (2001). For this, the abdomens were individually subjected to ground-glass homogenization in $1 \mathrm{ml}$ distilled water and then centrifuged at $1500 \mathrm{~g}$ for $5 \mathrm{~min}$. Aliquots of supernatant were tested for soluble protein by the dye-binding method of Bradford (1976) using BioRad Dye Reagent (BioRad Labs. $\mathrm{GmbH}$ ) and bovine serum albumin as standard (Sigma [fractionV, 98\%]) (Anon, 1979).

\section{Nosema ceranae development}

Forager bees were sampled outside the entrance of the hives at midday (time of sampling in Tab. 1). The entrance of each hive was closed with a foam rubber so that foraging bees could be collected inside a flask with ethanol $70^{\circ}$. In the laboratory, the abdomens of 30 bees per combination of each colony, treatment and time were individually homogenized in $1 \mathrm{ml}$ of distilled water and checked for the presence of Nosema spores to obtain prevalence (percentage of infected bees per hive, colony level; adapted from Smart \& Sheppard, 2012) and intensity (number of mature spores per bee, individual 
level; Undeen \& Vávra, 1997). The homogenates were observed in a Neubauer hemocytometer under a compound microscope $(x 400)$ to quantify the number of mature spores (Cantwell, 1970).

\section{Statistical analysis}

A Restricted Maximum Likelihood (REML) analysis and residual plots were used to select Linear Mixed Effects (LME) models with the best fitting to each variable. The hive was considered by random effects and treatment, time and their interaction by fixed effects. Bees were included as a random effect to the analysis of soluble proteins and fat body mass. Where necessary, a different variance function was used to model the variance structure of the errors within each group. The effects of treatments were analyzed by ANOVA using R software (version 3.1.1, 2014). Mean values of variables, standard deviation and least significant differences were calculated using the best-fit model. In the case in which treatment did not present significant differences, respect to the control the mean between both groups was considered. Differences among treatments were evaluated using the studentized range Tukey method ( $p<0.05$ ).

\section{RESULTS}

\section{Bacterial metabolites characterization and quantification}

The organic acids produced by L. johnsonii AJ5 present in the CFS were detected by HPLC. The compounds identified and their concentrations were lactic acid (275 $\pm 8 \mathrm{mM})$, phenyl-lactic acid $(0.4 \pm 0.1 \mathrm{mM})$ and acetic acid $(40 \pm 5 \mathrm{mM})$.

\section{Toxicity of bacterial metabolite on honey bees}

The administration of CFS under laboratory conditions did not produce considerable bee mortality so no statistical analyses were performed. After $72 \mathrm{~h}$ of exposure, none of the cases, had a mortality rate over $10 \%$. Both controls showed a mortality rate of $3 \%$ at 72 $\mathrm{h}$ while the highest doses of CFS treatment reached only $6 \%$.

\section{Effects of CFS on colony development}

Regarding the colony development parameters, it was not necessary to model the variance structure of the errors within group. Treatment and interaction treatment $x$ time did not produce significant changes in each studied parameter (ANOVA, $p>0.05$ ). An increase in adult bee population from $5.0 \pm 0.3$ to $8.9 \pm 0.3$ was observed from T0 to T4. Similarly, sealed brood combs increased from $2.34 \pm 0.19$ to 3.95 \pm 0.19 (from T0 to T4). Considering open brood, the mean varied throughout the field trial from $1.66 \pm 0.25$ to $2.85 \pm 0.25$. An increase over time could be observed in both groups for the variables except honey and pollen storage (ANOVA, $p=0.74, p=0.09$ respectively), with significant differences over time but not between treatments (Tab. 2).

\subsection{Effects of CFS on fat bodies of worker bees}

For fat bodies, the heterogeneity of the fitted values was modeled. Fat body development decreased with time (ANOVA, $p=0.008$ ) without any differences between CFS and MRS administrations at the end of the trial ( $T_{4}$ ANOVA, $\mathrm{p}=0.13)$. Worker bees decreased their fat bodies

Table 2

Colony development parameters. Values are mean \pm standard error. Different letters represent differences between times $(p<0.05)$. $T_{0}$ : initial time, $T_{2}$ : two weeks after the start of trial, $T_{4}$ : five weeks after the start of trial

\begin{tabular}{lccc}
\hline & $\mathbf{T}_{\mathbf{0}}$ & $\mathbf{T}_{2}$ & $\mathbf{T}_{4}$ \\
Adult bees & $5.00 \pm 0.30 \mathrm{a}$ & $7.25 \pm 0.30 \mathrm{~b}$ & $8.95 \pm 0.30 \mathrm{c}$ \\
Sealed brood & $2.34 \pm 0.19 \mathrm{a}$ & $3.14 \pm 0.19 \mathrm{~b}$ & $3.95 \pm 0.19 \mathrm{c}$ \\
Open brood & $1.66 \pm 0.25 \mathrm{a}$ & $2.40 \pm 0.25 \mathrm{ab}$ & $2.85 \pm 0.25 \mathrm{~b}$ \\
Honey & $0.55 \pm 0.14 \mathrm{a}$ & $0.64 \pm 0.14 \mathrm{a}$ & $0.70 \pm 0.14 \mathrm{a}$ \\
Pollen & $0.35 \pm 0.12 \mathrm{a}$ & $0.39 \pm 0.12 \mathrm{a}$ & $0.52 \pm 0.12 \mathrm{a}$ \\
\hline
\end{tabular}




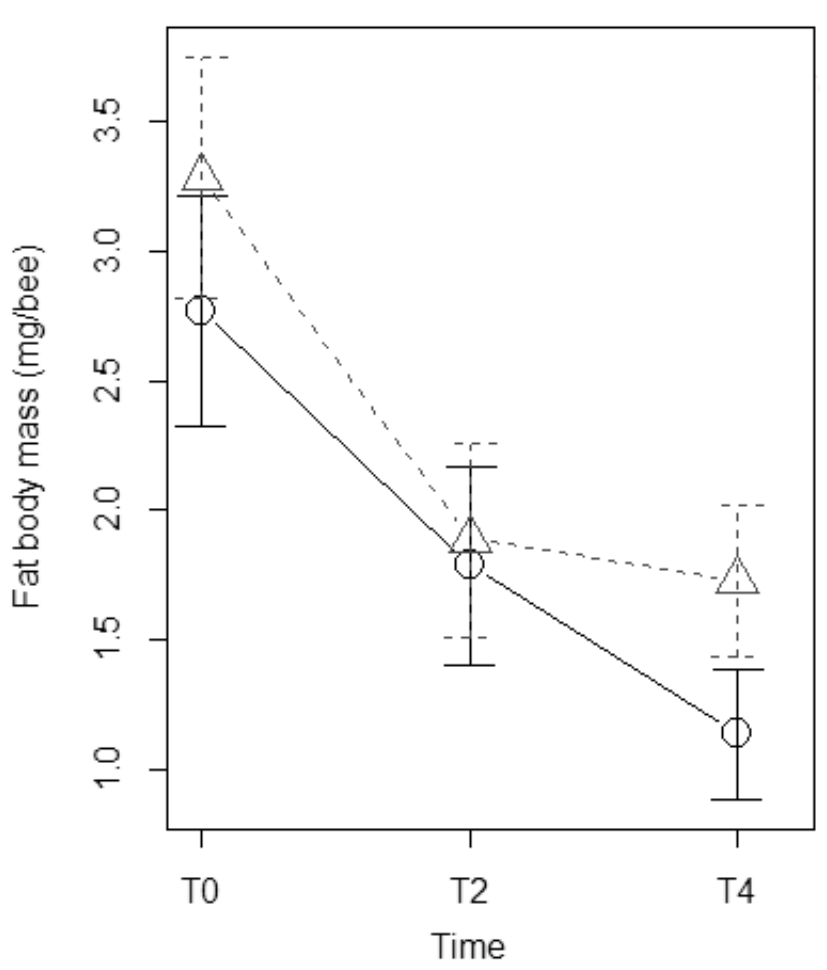

Fig. 1. Fat body per bee for different treatments and sampling time. Circles: means of bees which received MRS plus syrup 2.1; triangles: means of bees which received CFS plus syrup 2:1. T0: initial time, T2: two weeks after the start of trial, T4: five weeks after the start of trial. Bars indicate mean standard error.

reserves from $2.9 \pm 0.4\left(T_{0}\right)$ to $1.7 \pm 0.3 \mathrm{mg} / \mathrm{bee}$ $\left(T_{2}\right)$ Fat bodies reserves decreased towards the last sampling time $\left(T_{4}, 1.3 \pm 0.2 \mathrm{mg} / \mathrm{bee}\right.$, Fig. 1).

\section{Effects of CFS on soluble protein content} of worker bees

For the protein content, the heterogeneity of time factor covariance was modeled. CFS did not produce a significant change on soluble protein content compared with the control group (ANOVA, $p=0.11$ ). Soluble protein content had significant differences only among times $\left(\mathrm{T}_{0}, \mathrm{~T}_{2}\right.$ and $\left.\mathrm{T}_{4}\right)$ (ANOVA, $\left.\mathrm{p}<0.01\right)$. A decreasing trend was observed from $0.013 \pm 0.0006 \mathrm{mg} /$ $\mathrm{mg}\left(\mathrm{T}_{0}\right)$ to $0.009 \pm 0.0004 \mathrm{mg} / \mathrm{mg}\left(\mathrm{T}_{2}\right)$. After the time of $T_{2}$ sampling, both groups presented an increased in soluble protein content up to 0.013 $\pm 0.0007 \mathrm{mg} / \mathrm{mg}\left(\mathrm{T}_{4}\right)$.

\section{Effects of CFS on $\boldsymbol{N}$. ceranae development} The modelling of the structure of fitted values variance was necessary for $N$. ceranae intensity but not for $N$. ceranae prevalence. It was similar for treated and control groups of colonies. At the beginning of the trial, it was $74 \%$ for both groups and by the end of the experimental period $\left(T_{4}\right)$ it had decreased on average to $42 \%$ (ANOVA, p<0.05). Significant differences were not observed between treatments (ANOVA, $p=0.46)$, but a trend to a major reduction was observed for CFS administration (Fig. 2). $N$. ceranae intensity decreased over time in both groups of colonies. The average of number of Nosema spores at the initial level $\left(T_{0}\right)$ was $1.7 E+06 \pm 1.6 E+05$ in the control group and $1.0 \mathrm{E}+06 \pm 1.1 \mathrm{E}+05$ in the treated hives (ANOVA, $p<0.05)$. At the end of the experiment $\left(T_{4}\right)$, colonies fed with the CFS decreased the number of spores to $1.4 \mathrm{E}+05 \pm 5.2 \mathrm{E}+04$ and colonies fed with the MRS culture to $1.5 E+05 \pm 5.3 E+04$ (ANOVA, $p<0.05$ ).

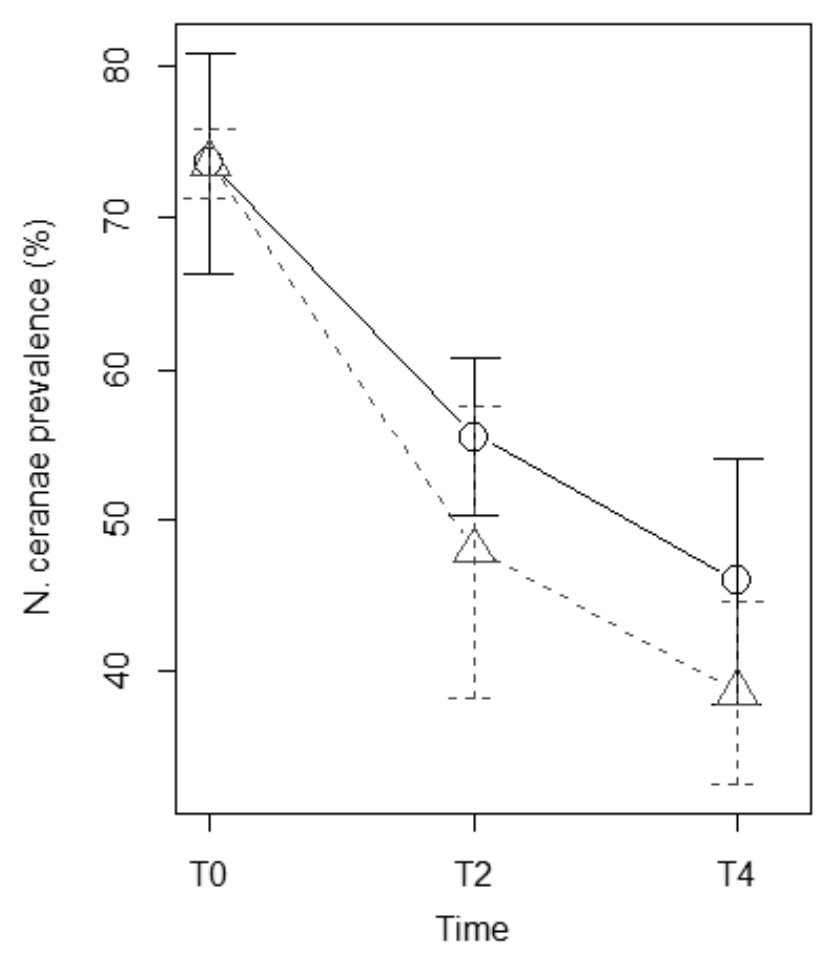

Fig. 2. Nosema ceranae prevalence (percentage of infected bees per hive) for different treatments and sampling time. Circles: means of percentage of infected bees per colony which received MRS plus syrup 2.1; triangles: means of percentage of infected bees per colony which received CFS plus syrup 2:1. T0: initial time, T2: two weeks after the start of trial, T4: five weeks after the start of trial. Bars indicate mean standard error. 


\section{DISCUSSION}

Knowledge on the composition and functions of the bee gut microbiota and the link between a balanced gut microbiota and health status has been increasing over the last years together with the continuous decline of honey bees' colonies (Alberoni et al., 2016; Mattila et al., 2012). In this regard, some bacterial strains and products of their metabolism have begun to receive special scientific attention. Some studies have reported beneficial effects of microbiota on bees' health (Mattila et al., 2012; Janashia \& Alaux, 2016) and undesirable effects particularly on microbial threats (Forsgren et al., 2009; Vásquez et al., 2012; Baffoni et al., 2015; Audisio, 2016).

Our study was focused on assessing the effect of bacterial metabolites produced by a LAB (L. johnsonii AJ5) on nutritional parameters, $N$. ceranae development and performance of A. mellifera colonies. LAB belonging to honey bee gut microbiota was selected on the basis of its production of organic acids (Audisio et al., 2011) and its beneficial effects on honey bees (Audisio \& Benítez, 2011; Maggi et al., 2013; Audisio et al., 2015).

We observed that CFS in high doses is not lethal after $72 \mathrm{~h}$ of bee exposure. All populations' parameters increased at the end of the trial without treatments effects. This result differed from previous reports in which not only bee gut bacteria had been administered inside beehives but also their metabolites. Maggi et al. (2013) had found that colonies fed with a CFS produced by Lactobacillus johnsonii CRL1647 increased their beehive population compared with untreated colonies. One of the differences between these two studies was the use of distinct strains of the same bacterial species. Even though both are $L A B$ and behave differently, they produce the same main organic acids but in different concentrations. Apart from that, the responses of colonies to the CFS could have been influenced by the application season. In the mentioned study, a higher organic acid dose than this trial was supplied at the beginning of winter. In summary, the main difference between the results of both studies could have been caused by the concentration of
CFS administered and secondly the application season. Furthermore, beneficial effects were observed in colonies if the direct bacterium administration instead of its metabolites is considered. An increase in honey yield and a reduction in nosemosis and varroosis incidence were detected by the administration of a Lactobacillus johnsonii CRL1647 culture (Audisio et al., 2015). Also, Sabaté et al. (2012) reported an increase in the honey bee population and a decline in bee diseases worldwide when colonies were fed with a Gram-positive bacterium found in honey (Bacillus subtilis subsp. subtilis Mori2). These effects could have been influenced by the interaction between the microorganisms belonging to the bee microbiota (Mattila et al., 2012; Vásquez et al., 2012; Audisio, 2016).

The nutritional status of individual bees was also analyzed consisting of two parameters: fat bodies and soluble protein content on the abdomen. The former corresponded to an organ in bees that was related with the storage of lipids and proteins required for different metabolic activities (de Oliveira \& da Cruz-Landim, 2003), synthesis of different proteins like vitellogenin (Amdam \& Omholt, 2002; Corona et al., 2007) and humoral immune by the synthesis of antimicrobial peptides (Brown, Moret \& Schmid-hempel, 2003; Wilson-Rich, Dres \& Starks, 2008). The major component of fat body is lipid representing more than $50 \%$ of dry weight and being a measure of bee health (Arrese \& Soulages, 2010). We found no differences in the lipid mass on bees being fed SLC and MRS but a decreasing trend was observed over time. This result differs from the increase on fat body mass found by Maggi et al. (2013) in bees supplemented with bacterial metabolites. As mentioned before, these differences were probably based on the lower concentration of organics acids administered in this research. The content of soluble proteins in abdomen was the other parameter of nutritional status of bees and its content did not change between treatments or overtime. This suggests that bacterial metabolites utilized in this study maintained the nutrition status of bees at this specific CFS concentration in spring. Further assays including wide doses of bacterial metabolites would be necessary in order to 
clarify this response.

Regarding to $N$. ceranae presence, colony and individual levels were studied, and results showed that the administration of CFS did not affect the individual level of the disease. There was a decrease in the number of Nosema spores per bee over time with no significant differences between CFS and MRS supplementation. However, a reduction trend of CFS was observed at colony level when compared to MRS treatment. Literature has shown enough evidence about the effect of bacteria or their metabolites on Nosema spp. viability. A combination of two non-pathogenic bacteria, bifidobacteria and lactobacilli, administered to $N$. ceranae-infected bees showed a reduction in parasitism level (Baffoni, et al., 2015). In the same way, Corby-Harris et al. (2016) discovered an increased resistance to Nosema infection by bees fed a hive bacterium. Concerning bacterial metabolites, Porrini et al. (2010) suggested that a surfactin could damage the spore external structure decreasing their viability. Maggi et al. (2013) as well proposed a hypothesis about the alteration of microsporidium envelope by an organic acid.

In summary, some studies indicate that a mutualistic relationship between bee and microbiota is essential in the development of colonies (Mattila et al., 2012; Vásquez et al., 2012). The current study shows a tendency of clarifying this knowledge since the concentration of CFS administered was not ideal. Taking it into account and considering the beneficial properties of nonpathogenic bacteria and their metabolites, more assays would be necessary to adjust the concentration of CFS supplied in order to detect significant effects on the parameters evaluated. In this sense, other physiological parameters should be assessed for the best understanding of the relationship between bacterial metabolites and the nutritional and immune status of the bees.

\section{ACKNOWLEDGMENTS}

The authors wish to thank Gabriela Cendoya B.Sc. (Agr.) and Raúl González Belo B.Sc. (Agr.) for their assistance in statistical analyses, Mariana Bianculli B.Sc. (Agr.) for the revision of English style and Dr. Martín Porrini for his advice on research design. The authors also acknowledge Consejo Nacional de Investigaciones Científicas y Técnicas (CONICET) and Unidad Integrada Balcarce (UIB). This research was supported by a PICT2012-0594 (FONCyT) grant to Dr. Martín Eguaras.

\section{REFERENCES}

Alaux, C., Brunet, J. L., Dussaubat, C., Mondet, F." Tchamitchan, S., Cousin, M., Brillard, J., Baldy, A., Belzunces, L. P., Le Conte, Y. (2010a). Interactions between Nosema microspores and a neonicotinoid weaken honeybees (Apis mellifera). Environmental Microbiology, 12, 774-782. doi:10.1111/j.14622920.2009.02123.x.

Alaux, C., Ducloz, F., Crauser, D., Le Conte, Y. (2010b). Diet effects on honeybee immunocompetence. Biology Letters, 6 (4), 562-565.

Alberoni, D., Gaggìa, F., Baffoni, L., Di Gioia, D. (2016). Beneficial microorganisms for honey bees: problems and progresses. Applied Microbiology and Biotechnolology, 100, 9469-9482. doi: 10.1007/s00253016-7870-4.

Amdam, G. V., \& Omholt, S. W. (2002). The Regulatory Anatomy of Honeybee Lifespan. Journal Theoretical Biology, 216, 209-228.

Anon (1979). BioRad Laboratories Bulletin 1069: BioRad protein assay instruction manual. BioRad Laboratories, Richmond, California, USA. 17pp.

Antúnez, K., Martín-Hernández, R., Prieto, L., Meana, A., Zunino, P., Higes, M. (2009), Immune suppression in the honey bee (Apis mellifera) following infection by Nosema ceranae (Microsporidia). Environmental Microbiology, 17, 2284-2290. doi:10.1111/j.14622920.2009.01953.x.

Arrese, E. L., \& Soulages, J. L. (2010). Insect Fat Body: Energy, Metabolism, and Regulation. Annual Review of Entomology, 55, 207-25. doi: 10.1146/annurev- 


\section{J. APIC. SLI. VUL. 61 ND. 12017}

ento-112408-085356.

Audisio, C. M. (2016). Gram-Positive Bacteria with Probiotic Potential for the Apis mellifera L. Honey Bee: The Experience in the Northwest of Argentina. Probiotics and Microbials Proteins, 1-10. doi: 10.1007 / s12602-016-9231-0.

Audisio, M. C., \& Benítez-Ahrendts, M. R. (2011). Lactobacillus johnsoniiCRL1647, isolated from Apis mellifera L. bee-gut, exhibited a beneficial effect on honeybee colonies. Beneficial Microbes, 2(1), 29-34.

Audisio, M. C., Torres, M. J., Sabaté, D. C., Ibarguren, C., Apella, M. C. (2011). Properties of different lactic acid bacteria isolated from Apis mellifera L. beegut. Microbiological Research, 7, 1-13.

Audisio, M. C., Sabaté, D. C., Benítez-Ahrendts, M. R. (2015). Effect of Lactobacillus johnsonii CRL1647 on different parameters of honeybee colonies and bacterial populations of the bee gut. Beneficial Microbes, 25, 1-10. doi: 10.3920/BM2014.0155

Baffoni, L., Gaggìa, F., Alberoni, D., Cabbri, R., Nanetti, A., Biavati, B., Di Gioia, D. (2016). Effect of dietary supplementation of Bifidobacterium and Lactobacillus strains in Apis mellifera L. against Nosema ceranae. Benefical Microbes, 71), 45-51. doi:10.3920/BM2015.0085

Bogdanov, S. (2006). Contaminants of bee products. Apidologie, 37,1-18.

Bowen-Walker, P. L., \& Gunn, A. (2001). The effect of the ectoparasitic mite, Varroa destructor on adult worker honeybee (Apis mellifera) emergence weights, water, protein, carbohydrate, and lipid levels. Entomologia Experimentalis et Applicata, 107(3), 207-217.

Bradford, M. (1976). A rapid and sensitive method for the quantification of microgram quantities of protein utilizing the principle of protein dye-binding. Annals of Biochemistry, 72, 248-254.

Branco, M. R., Kid, N. A. C., \& Pickard, R. S. (1999). De- velopment of Varroa jacobsoni in colonies of Apis mellifera iberica in a Mediterranean climate. Apidologie, 30,491-503.

Brodschneider, R., \& Crailsheim, K. (2010). Nutrition and health in honey bees. Apidologie, 47(3), 278-294.

Brown, M. J. F., Moret, Y., \& Schmid-hempel, P. (2003). Activation of host constitutive immune defence by an intestinal trypanosome parasite of bumble bees. Parasitology, 126, 253-260.

Cantwell, G. E. (1970). Standard methods for counting Nosema spores. American Bee Journal, 7106), 222-223.

Corby-Harris, V., Snyder, L., Meador, C. A., Naldo, R., Mott, B., Anderson, K. E. (2016). Parasaccharibacter apium, gen. nov., sp. nov., improves honey bee (Hymenoptera: Apidae) resistance to Nosema. Journal of Economic Entomology, doi:10.1603/ ICE.2016.94339

Corona, M., Velarde, R. A., Remolina, S., Adrienne Moran-Lauter, A., Wang, Y., Hughes, K. A., Robinson, G. E. (2007). Vitellogenin, juvenile hormone, insulin signaling, and queen honey bee longevity. National Academy of Sciences, 104(17), 7128-7133.

Crotti, E., Balloi, A., Hamdi, C., Sansonno, L., Marzorati, M., Gonella, E., Favia, G., Cherif, A., Bandi, C., Alma, A., Daffonchio, D. (2012). Microbial symbionts: a resource for the management of insect-related problems. Microbiology Biotechnology, 5, 307-317. doi:10.1111/j.1751- 7915.2011.00312.x.

de Oliveira, V. T. P., \& da Cruz-landim, C. (2003). Morphology and function of insect fat body cells: a review. Biociências, 77 (2), 195-205.

Dillon, R. J., \& Dillon, V. M. (2004). The gut bacteria of insects: Nonpathogenic Interactions. Annual Review of Entomology, 49, 71-92.

Ellers, J. (1996). Fat and eggs: an alternative method to measure the trade-off between survival and reproduction in insect parasitoids. Netherlands 


\section{— DE PIAND ET Hl. _ Bacterial metabolites effects on honey bees}

Journal of Zoology, 46, 227-235.

Engel, P., Martinson, V. G., Moran, N. A. (2012). Functional diversity within the simple gut microbiota of the honey bee. Proceedings of the National Academy of Sciences of the United States of America, 10927), 11002-11007.

Evans, J. D., \& Lopez, D. L. (2004). Bacterial probiotics induce an immune response in the honey bee ( $\mathrm{Hy}$ menoptera: Apidae). Journal of economic entomology, 973), 752-6.

Forsgren, E., Olofsson, T. C., Vásquez, A., Fries, I. (2009). Novel lactic acid bacteria inhibiting Paenibacillus larvae in honey bee larvae. Apidologie, 47(1), 99-108.

Forsgren, E., Fries, I. (2010). Comparative virulence of Nosema ceranae and Nosema apis in individual European honey bees. Veterinary Parasitology, 170, 212-217. doi:10.1016/j.vetрar.2010.02.010

Fries, I. (1988). Infectivity and multiplication of Nosema apis z. in the ventriculus of the honey bee. Apidologie, 19(3), 319-328.

Fries, I. (2010). Nosema ceranae in European honey bees (Apis mellifera). Journal of Invertebrate Pathology, 103, s73-s79.

Fries, I. F., da Silva, A., Slemenda, S. B., Pieniazek, N. J. (1996). Nosema ceranaen. sp. (Microspora, Nosematidae), Morphological and Molecular Characterization of a Microsporidian Parasite of the Asian Honey bee Apis cerana (Hymenoptera, Apidae). European Journal of Protistology, 32(3), 356-365.

Gündüz, E. A., \& Douglas, A. E. (2009). Symbiotic bacteria enable insect to use a nutritionally inadequate diet. Proceedings of the Royal Society London Biology Science, 276, 987-991. doi:10.1098/ rspb.2008.1476

Higes, M., Martín, R., \& Meana, A. (2006). Nosema ceranae, a new microsporidian parasite in honeybees in Europe. Journal of Invertebrate Pathology, 92, 93-95.
Higes, M., García-Palencia, P., Martín-Hernández, R., Meana, A. (2007). Experimental infection of Apis mellifera honeybees with Nosema ceranae (Microsporidia). Journal of Invertebrate Pathology, 94, 211-217.

Higes, M., Martín-Hernández, R., Botías, C., Bailón, E. G., González-Porto, A. V., Barrios, L., del Nozal, M. 」., Bernal, J. L., Jiménez, J. I., Palencia, P. G., Meana, A. (2008). How natural infection by Nosema ceranae causes honeybee colony collapse. Environmental Microbiology, 10, 2659-2669. doi:10.1111/j.14622920.2008.01687.x

Janashia, I., \& Alaux, C. (2016). Specific Immune Stimulation by Endogenous Bacteria in Honey Bees (Hymenoptera: Apidae). Journal of Economic Entomology, 1-4. doi: 10.1093/jee/tow065.

Jefferson, J. M., Dolstad, H. A., Sivalingam, M. D., Snow, J. W. (2013). Barrier immune effectors are maintained during transition from nurse to forager in the honey bee. PLoS One, 8(1), e54097. doi:10.1371/journal. pone.0054097

Maggi, M., Ruffinengo, S., Damiani, N., Sardella, N., Eguaras, M. (2009). First detection of Varroa destructor resistance to coumaphos in Argentina. Experimental and Applied Acarology, 47, 317-320.

Maggi, M., Ruffinengo, S., Negri, P., Eguaras, M. (2010). Resistance phenomena to amitraz from populations of the ectoparasitic mite Varroa destructor of Argentina. Parasitology Research, 107,1189-1192.

Maggi, M., Ruffinengo, S., Mendoza, Y., Ojeda, P., Ramallo, G., Floris, I., Eguaras, M. (2011). Susceptibility of Varroa destructor (Acari: Varroidae) to synthetic acaricides in Uruguay: Varroa mites' potential to develop acaricide resistance. Parasitology Research, 108, 815-821.

Maggi, M., Negri, P., Plischuk, S., Szawarski, N., De Piano, F., De Feudis, L., Eguaras, M., Audisio, C. (2013). Effects of the organic acids produced by a lactic acid bacterium in Apis mellifera colony development, Nosema ceranae control and fumagillin efficiency. Vet- 


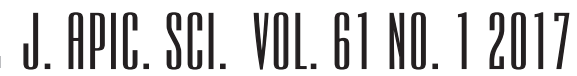

erinary Microbiology, 167,474-483.

Mattila, H. R., Rios, D., Walker-Sperling, V. E., Roeselers, G., Newton, I. L. G. (2012). Characterization of the active microbiotas associated with honey bees reveals healthier and broader communities when colonies are genetically diverse. PLOS ONE, 73), e32962. doi:10.1371/journal.pone.0032962

Medici, S. (2010.) Determinación del contenido de residuos de acaricidas y antibióticos en miel y cera en colmenares argentinos destinados a la producción. Suplemento APINOTIC\&AS2.

Moran, N. A. (2015). Genomics of the honey bee microbiome. Current Opinion in Insect Science, 10, 22-28. doi:10.1016/j.cois.2015.04.003

Naug, D. (2009). Nutritional stress due to habitat loss may explain recent honeybee colony collapses. Biological Conservation, 142 (10), 2369-2372.

Neumann, P., \& Carreck, N. L. (2010). Honey bee colony losses. Journal of Apicultural Research, 49(1), 1-6.

Newton, I. L., Sheehan, K. B., Lee, F.., Horton, M. A., Hicks, R. D. (2013). Invertebrate systems for hypothesis-driven microbiome research. Microbiome Science and Medicine, 7(1). doi:10.2478/micsm-2013-0001

Oldroyd, B. P., (2007). What's killing American honey bees? PLoS Biology, 5(6), e168. doi:10.1371/journal. pbio.0050168.

Paxton, R. (2010). Does infection by Nosema ceranae cause "Colony Collapse Disorder" in honey bees (Apis mellifera)? Journal of Apicultural Research, 49(1), 80-84. doi: 10.3896/IBRA.1.49.1.11

Porrini, M. P. Audisio, M. C., Sabaté, D. C., Ibarguren, C., Medici, S. K., Sarlo, E. G., Garrido, P. M., Eguaras, M. (2010). Effect of bacterial metabolites on microsporidian Nosema ceranae and on its host Apis mellifera. Parasitology research, 1072), 381-8.

Sabaté, D. C., Carrillo, L., \& Audisio, M. C. (2009). Inhibition of Paenibacillus larvae and Ascosphaera apis by Bacillus subtilis isolated from honeybee gut and honey samples. Research in Microbiology, 160, 193199.

Sabaté, D. C., Cruz, M. S., Benítez-Ahrendts, M. R., Audisio, M. C. (2012). Beneficial Effects of Bacillus subtilis subsp. subtilis Mori2, a Honey-Associated Strain, on Honeybee Colony Performance. Probiotics and Antimicrobial Proteins, 4, 39-46.

Simion, G., Trif, A., Cara, M. C. \& Damiescu, L. (2011). Evaluation of tetracyclines' and cloramphenicol's residues levels in honey from Timis County between 2007 and 2010. (1), 264-269.

Smart, M., \& Sheppard, M. (2012). Nosema ceranae in age cohorts of the western honey bee (Apis mellifera). Journal of Invertebrate Pathology, 109, 148151.

Undeen, A. H., \& Vávra, J. (1997). Research methods for entomopathogenic Protozoa. Manual of Techniques in Insect Pathology. Academic Press, London. pp. 117-151.

vanEngelsdorp, D., Evans, J. D., Saegerman, C., Mullin, C., Haubruge, E., Nguyen, B. K., Frazier, M., Frazier, J., Coxfoster, D., Chen, Y., Underwood, R. M., Tarpy, D. R., Pettis, J. S. (2009). Colony Collapse Disorder: a descriptive study. PloS ONE, 4(8), e6481. doi:10.1371/ journal.pone.0006481

Vásquez, A., Forsgren, E., Fries, l., Paxton, R., Flaberg, E., Szekely, L., Olofsson, T. C. (2012). Symbionts as major modulators of insect health: lactic acid bacteria and honeybees. PLoS ONE, 7(3), e33188. doi: 10.1371 / journal.pone.0033188

Wilson-Rich, N., Dres, S. T., \& Starks, P. T. (2008). The ontogeny of immunity: development of innate immune strength in the honey bee (Apis mellifera). Journal of insect physiology, 54(10-11), 1392-9.

Yoshiyama, M., \& Kimura, K. (2009). Bacteria in the gut of Japanese honeybee, Apis cerana japonica, and their antagonistic effect against Paenibacillus larvae, the causal agent of American foulbrood. Journal of Invertebrate Pathology, 102, 91-96. doi:10.1016/j. jip.2009.07.005 


\section{_ DE PIANO ET HL. _ Bacterial metabolites effects on honey bees}

Yoshiyama, M., Sugimura, Y., Takaya, N., Kimoto-Nira, H., Suzuki, C. (2013). Inhibition of Paenibacillus larvae by lactic acid bacteria isolated from fermented materials. Journal of Invertebrate Pathology, 112,62-67. doi:10.1016/j.jip.2012.09.002 